\title{
Post Scriptum: Wider Perspectives and the Legacy
}

\author{
Torben R. Christensen, Margareta Johansson, \\ Christer Jonasson
}

This Special Report has presented work that we have chosen to categorize under the three M's, monitoring, manipulation, and modeling, promoted by Terry V. Callaghan through his time as Director of Abisko Scientific Research Station. As such, the issue also reflects the significant development in environmental science in general that has taken place over the past 40 years. From the growing realization of the value in maintaining long-term monitoring efforts, over the rapid development of manipulative experimental work in the 1980s and 1990s, through to the recent merging of all of this as useful data for validating ecosystem modeling efforts providing projections of future change. The Special Report has also shown examples of how the maintenance and communication of the long-term records as well as how the heritage of the early conceptual development and practical implementation of experimental manipulations at Abisko carry a heritage that has been taken up and used in other parts of the world. Although we are proud to have presented a substantial Special Report, it can still only be considered a mere reflection or miniscule corner of the volume of work along these same lines that has appeared in recent decades. This will be maintained as the legacy of Terry V. Callaghan's continued engagement in research in the Abisko area and circumpolar Arctic as a whole. Terry V. Callaghan has been instrumental in all these aspects through the decades. Terry V. Callaghan initiated own measurements in both subpolar environments in the late 1960s as part of the International Biological Program that has recently shown extremely valuable for multi-decadal scale comparisons of ecosystem change in the International Polar Year Back to The Future (BTF) context (referred to in several places in this issue and has been feeding a recent special $A M B I O$ issue). He went on to be amongst the pioneers, not the least in Abisko, exploring the use of ecosystem manipulative studies and in recent years he also have adopted work with modeling experts as an essential tool for helping bring all this together in a useful way for the predictions of the impacts in a changing environment. The latter, both at the large scale and not the least at the local scale where collaborations with Sami reindeer herders, for example, bring "science down to Earth" and where many practical problems for local people and useful predictions for their future is being unraveled-Terry V. Callaghan has been instrumental for it all. Along this historical sequence not only an extremely significant contribution to the international scientific community is present in itself (just as an example Terry holds the record number of papers published in $A M B I O$ ) but also a myriad of us in younger generations have benefited from the careful mentorship and inspiring continued commitment of Terry V. Callaghan to the supervision of future generations of scientists in this important area.

We, as guest editors, would like to thank all contributing authors to this Special Report. The commitment and engagement everybody has shown is a reflection on the important value of the legacy that the work in recent decades of Terry V. Callaghan is carrying. We struggled to stay within the limits of what is physically possible to print in $A M B I O$, another proof of the wish from the community to appreciate and celebrate the continued contribution of Terry V. Callaghan to all of our joint work.

Torben R. Christensen $(\square)$

Address: Lund University, Lund, Sweden.

e-mail: torben.christensen@nateko.lu.se

Margareta Johansson

Address: Lund University, Lund, Sweden.

\section{Christer Jonasson}

Address: Abisko Scientific Research Station, Swedish Polar Research Secretariat, Abisko, Sweden. 